\title{
PROMOTING SUSTAINABLE AND CIRCULAR PLASTICS USE IN EGIPT WITH IMPLEMENTATION OF ECODESIGN PRINCIPLES
}

\author{
doi: $\quad 10.2478 /$ czoto-2019-0057 \\ Date of submission of the article to the Editor: 05/12/2018 \\ Date of acceptance of the article by the Editor: 16/02/2019
}

Matevz Obrecht ${ }^{1}$ - orcid id: 0000-0001-8301-7382

Rawan El Haddad ${ }^{2}$ - orcid id: 0000-0002-5733-9000

Rowan Abd Elbary ${ }^{2}$

Rebeka Kovačič Lukman ${ }^{1}$ - orcid id: 0000-0001-6733-9584

Maja Rosi ${ }^{1}$ - orcid id: 0000-0003-4633-8237

1University of Maribor, Faculty of Logistics, Slovenia, matevz.obrecht@um.si

${ }^{2}$ Arab Academy for Science, Technology and Maritime Transport, Egypt

Abstract: Green Supply chain, Green Packaging, Eco-labels, and Eco-design strategies are concepts that are discussed frequently within scientific and political debates. Eco-design strategies for Lifecycle Design include the Eco-design Strategy wheel which presents eight Eco-design strategies: New concept development, Selection of low-impact materials, Reduction of materials usage, Optimization of production techniques, Optimization of distribution system, Reduction of impact during use, Optimization of initial lifetime, and Optimization of end-of-life system. This research investigates specifically the selection of low impact raw materials phase using the European Union as a benchmark to improve the Egyptian situation and aims to apply the closed loop cycle to the Egyptian Plastics Industry. Its goal is to enlight the way towards Sustainable and Circular economy system in Plastics manufacturing sector in Egypt while emphasizing the financial benefits from the Business and Marketing perspectives rather than the Environmental perspective only.

Keywords: Eco-design, Waste management, Plastics, sustainable consumption and production, Egypt

\section{INTRODUCTION}

Plastics are used in various sectors and have replaced plenty of materials, such as wood, leather, ceramic, metal, and glass. Many industries highly depend on the usage of Plastics such as Food, Healthcare, Shelter, Electronics, Aerospace, Construction, and Transportation. According to Association of Plastics Manufacturers, Plastics are in high demand due to its durability, flexibility, adaptability to be molded or shaped easily and its ability to be tailored physically or chemically. They are usually derived from natural, organic materials such as cellulose, coal, natural gas, salt and, of course, crude oil. 
As stated by World Energy Council (2016), The production of plastics is quite energy intensive, requiring sixty-two to one hundred and eight mega joules of energy per kilogram based on U.S. efficiency averages. It requires four basic steps: the acquirement of raw material, synthesizing a basic polymer, compounding the polymer into a usable fraction, and lastly, molding or shaping the plastic.
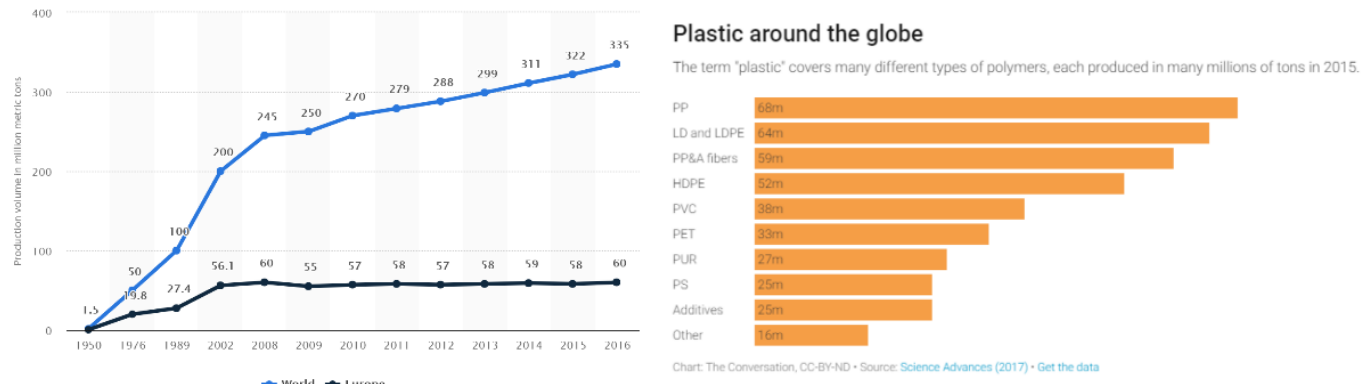

Fig.1. Global Plastics Production (Source: The Conversation, 2018)

As shown in Figure 1, The statistics depicts that Global plastics production in 2016 totaled around 335 million metric tons where 60 million metric tons were produced only in Europe (The Statistics Portal-Statista, 2018). The statistics also shows that the consumption of plastics in Africa had reached 9.7 million tons in 2015 where it is expected to reach over 13.4 million tons by 2021 due to more investments in plastics processing, urbanization rates, fast growing population and rising demands for packaging and packed goods (Plastex, 2018). Plastics is consumed by plenty of sectors as shown by the statistics in Figure 2.

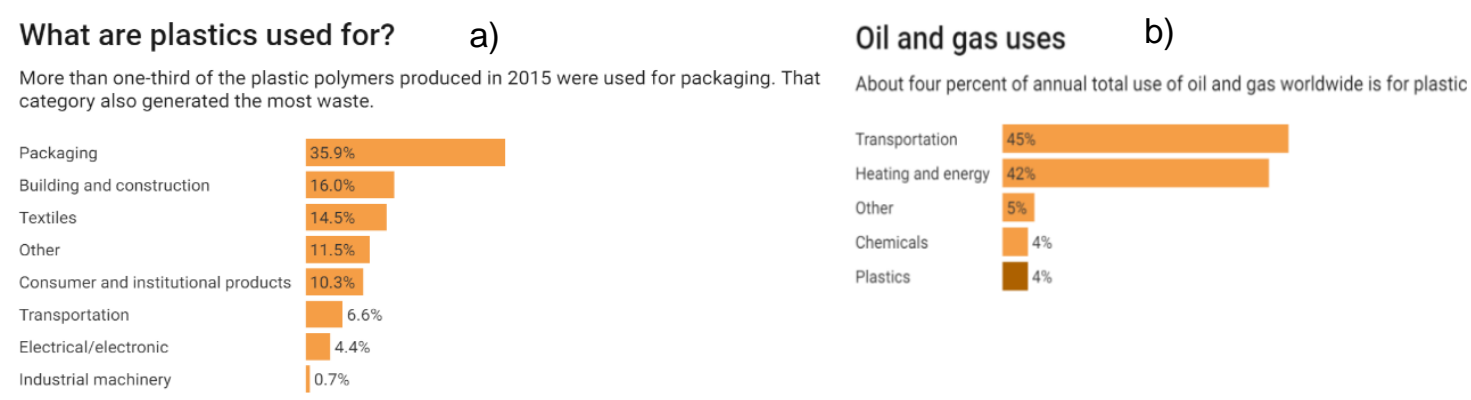

Fig.2. a) Plastics use and b) Oil and Gas uses (Source: The Conversation, 2018; WEF, 2018 and WEC, 2016)

In Egypt, there are more than 1200 plastics manufacturers who are all eager to the utmost developments in plastics machinery and technologies. Egypt is considered the gateway to the whole MENA region as it has the largest production capacity of all countries in Africa or as called the largest African polymer consuming country as it consumed 2.1 million tons of polymers in 2017 to be followed by South Africa, Kenya and Algeria with 1.84, 1.02, 0.81 million tons respectively (Plastex, 2018). According to Mohamed Taher, the executive director of the Egyptian Plastic Exporters and Manufacturers Association, "The plastics industry is growing very fast in Egypt, especially in the last decade, which has witnessed more investment, export activity, manpower and factory construction and the fastest-growing segments are plastic drainage pipes due to the growth of the construction sector" enabling many foreign manufacturers to seize plenty of opportunities to start or expand their business in Egypt (Oxford Business Group, 2011). 
The Egyptian Division of Plastics affiliated to the Federation of Egyptian Industries (FEI) stated that the total market volume of plastics in Egypt is US $\$ 4.03$ billion and total investments are reaching about US $\$ 4$ billion (Egyptian Plastic exporters and Manufacturers Association , 2009). Egypt consumed plastic materials and resins worth nearly US $\$ 1.6$ billion in 2016 (Plastex, 2018) which is actually more than all other North African countries (Algeria, Libya, Morocco and Tunisia) together. Demand is growing at $7.4 \%$ annually and the polymer demand is expected to reach 2.83 million tons by 2021 due to the increasing number of newly established projects and mega plants and the growing population demand (Plastex, 2018) as Egypt population is equivalent to $1.3 \%$ of the total world population, its currently about 100 million people based on the latest United Nations estimates. Egypt Growth Domestic Product (GDP) was worth 235.37 billion US dollars in 2017. The GDP value of Egypt represents 0.38 percent of the world economy and is projected to trend around 315.00 USD Billion in 2020 (Trading Economics, 2018) (Fig. 3a and Fig. 3b). Although, plastics are so durable and used in high quantities; They create considerable disposal problems (Hopewell et al., 2009). According to Nagwa El Maanawy, head of the Egyptian Plastic Technology Center, which is affiliated with the Ministry of Trade and Industry, Egypt's annual waste output, is about 16.2 million tons where six percent equivalent to 970 thousand tons is Plastics waste. Forty-five percent is recycled, only five percent reused, and fifty percent of plastic garbage is not sorted but instead incinerated, which is harmful to the environment (EgyptToday, 2018).

Therefore, this research aims to investigate the Selection of low impact raw materials phase to produce plastics according to Eco-design strategy wheel, apply the closed loop cycle to the Egyptian Plastics Industry to achieve sustainability and circular economy system in Egypt and emphasize the financial business benefits in the Egyptian market from the Marketing and Business perspectives rather than the Environmental perspective only while comparing the European Union achievements in the Plastics Industry as a benchmark to reduce the amount and impact of Plastics waste in Egypt.

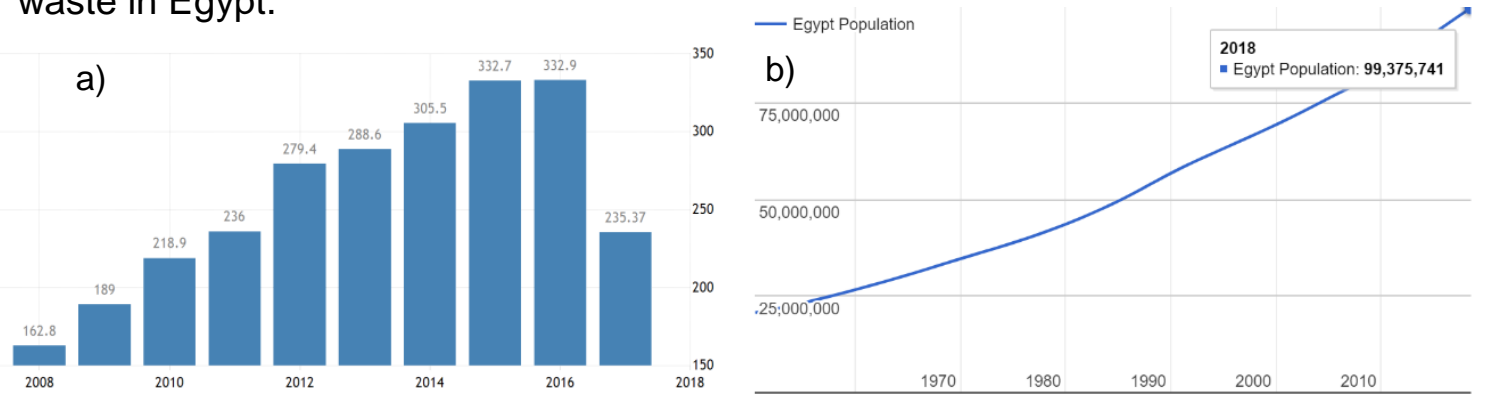

Fig.3. a) Egypt GDP and b) Egypt population (Trading Economics, 2018)

\section{EXPERIMENTAL}

Although plastic wastes are a global issue, the European Union (EU) sets some laws and follows procedures such as recycling, reusing, and reducing the amount of plastic wastes to protect the environment. Therefore, this research main purpose is to use the EU as a benchmark to improve the Middle Eastern situation specifically Egypt in terms of the high plastic wastes rates. Egypt will be the case study in this research to reduce the impact of plastic wastes on the environment by selecting low impact raw materials from the Eco design strategy wheel as an effective tool for applying the 
closed loop cycle to the Egyptian Plastics Industry to reach sustainability and circular economy system in Egypt while focusing on elevating the Financial situation in the Egyptian economy by increasing profits and decreasing costs and raising awareness to the general public as well to create new segments of customers that care about the environment tackling the Marketing Perspective.

\section{RESULTS AND DISCUSSION}

According to (Su et al, 2015), there are several ways Egyptian manufacturers can implement to reduce plastic wastes such as minimizing plastic consumption, recycling and reusing. It is essential to use plastic consumption calculator to set a target of how much needed to be reduced. Then, set specific strategies or solutions that help reaching this target such as selecting materials that have low impact on the environment from trusted suppliers, reducing the upstream plastic use in Egypt generally, purchasing in bulk to avoid unnecessary packaging of the products, using biodegradable materials, or reusable and refillable materials instead of single use plastic products to protect the environment.

Plastics usage audits should be conducted regularly to constantly focus on the target of decreasing plastic wastes and improving consistently. Also, conducting workshops and training programs in all functions in the Egyptian enterprises is a great way to emphasize the importance and benefits of reducing plastic wastes. As an example: Organizations can use water filters and glass cups instead of plastic water bottles for employees. Other smart solutions could be building partnerships with competitors or similar industries to close the loop and reduce plastics usage in operations and raising awareness by focusing on marketing the importance of reducing plastic wastes to change the Egyptian consumers' behavior to reuse products and consume more recycled products to have significant results in reducing plastic wastes amounts. Currently Egypt ranks on $7^{\text {th }}$ place out of all countries in the world according to mismanaging plastic wastes (Earth Day Network, 2018). Among 20 countries that mismanage plastic wastes, four are North African countries. This proves that plastic wastes are not treated properly in North Africa in general and especially in Egypt that is ranked highest within this classification (Our World in Data, 2018).

To avoid huge environmental impacts caused by plastic wastes, companies should use Life Cycle Assessment (LCA) method to assess the environmental aspects and potential impact of products and supply chains to reduce the impact of plastic wastes comprehensively (Matsuno, Y, and Kondo, 2008). This method allows possible improvements in the supply chain by compiling, evaluating and assessing all inputs and outputs. There are four main phases of the Life cycle assessment process. First, Goals and Scoping determine which environmental, economic, and social concerns and processes will be included. Second, Life cycle inventory provides information about all inputs and outputs in the product system. Third, Life cycle impact assessment collects inventory data and converts the indicators to impacts. Final phase and forth, Interpretation checks whether the impact data met the objectives or not. The purpose of using life cycle assessment is to reduce wastes, costs and negative environmental impacts (NRDC, 2018; B-Corporation, 2018).

Egyptian manufacturers should use the Eco design strategies as an effective tool to achieve minimum usage of plastic resources to have low impact on the environment to constantly meet the demands and save the scarce resources. Also, Egyptian manufacturers must follow those important environmental considerations depending 
on the industry and on the applicability of those considerations regarding operations (Fig. 4):

- Reducing the environmental impact of disposal

- Reducing the environmental impacts from distributing products

- Ensuring that products used does not cause high amount of wastes or lead to pollution

- Ensuring that products use fewer resources due to scarcity of materials

- Optimizing the product functions

- Reusing and recycling materials

- Using materials with less environmental impact in production

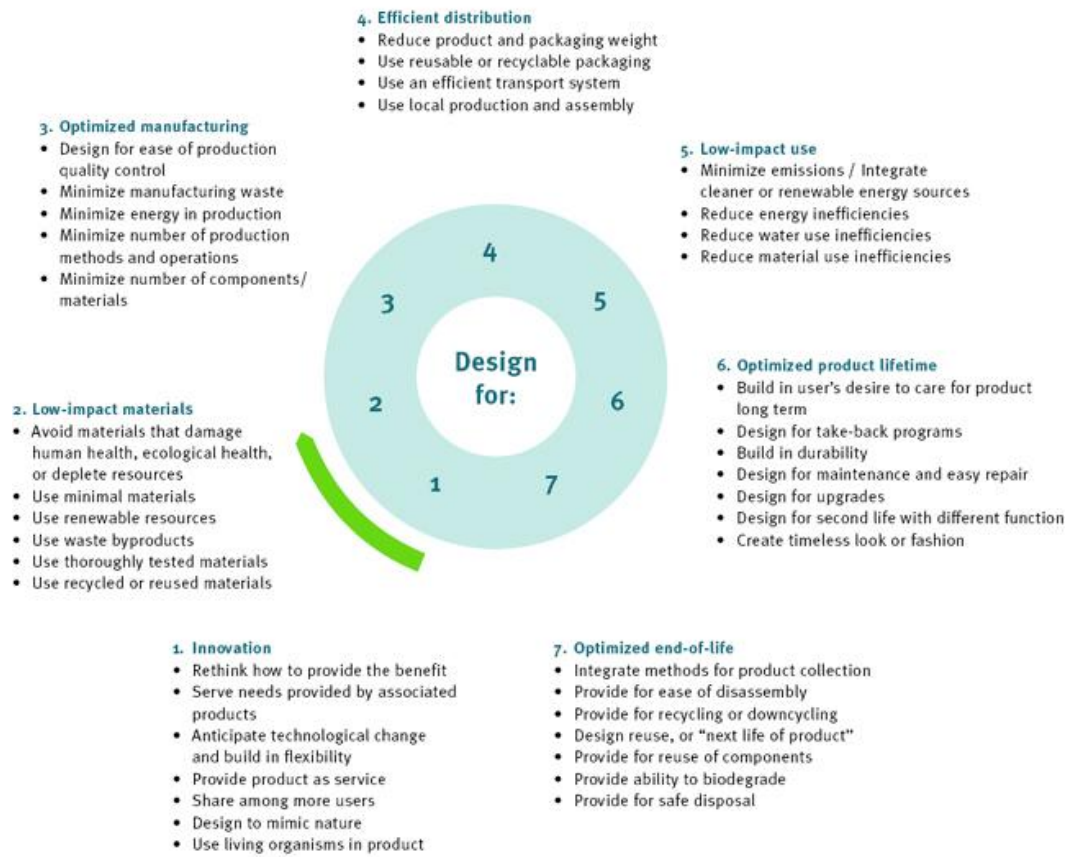

Fig. 4. Eco design strategy wheel (Sustainable minds, 2018; Okala.net, 2018)

Although there is significant amounts of plastic wastes generated in Europe as shown in Fig. 5, there is a huge amount that is recovered and recycled for various reasons yet mainly is to save the environment and reach sustainability. Therefore, EU will be used as a benchmark to improve Egypt's situation regarding minimizing plastic wastes.

Development of all packaging waste generated, recovered and recycled, EU, 2006-2015

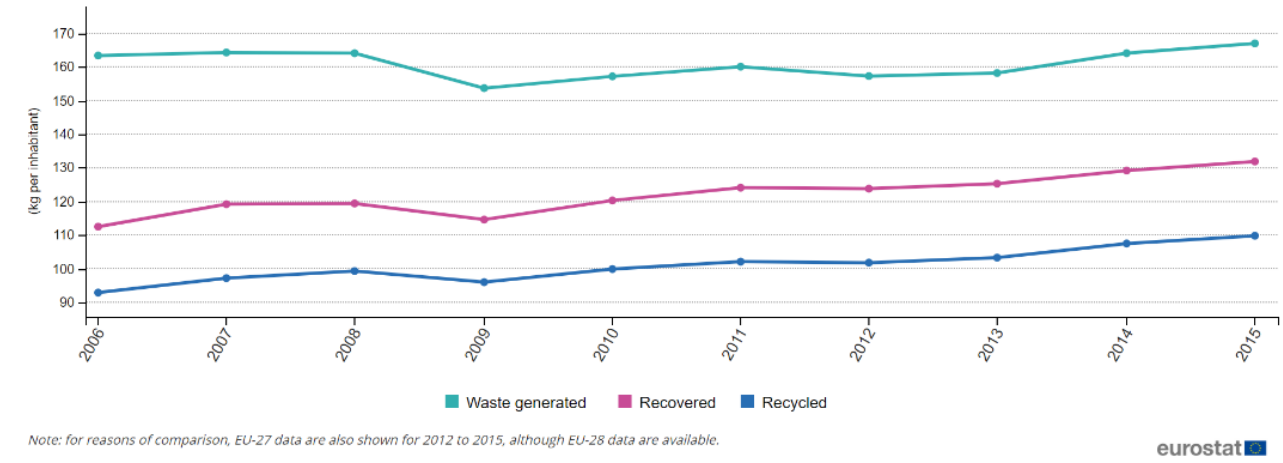

Fig. 5. European Union Packaging wastes generated, recovered, and recycled (Ec.europa.eu, 2018) 


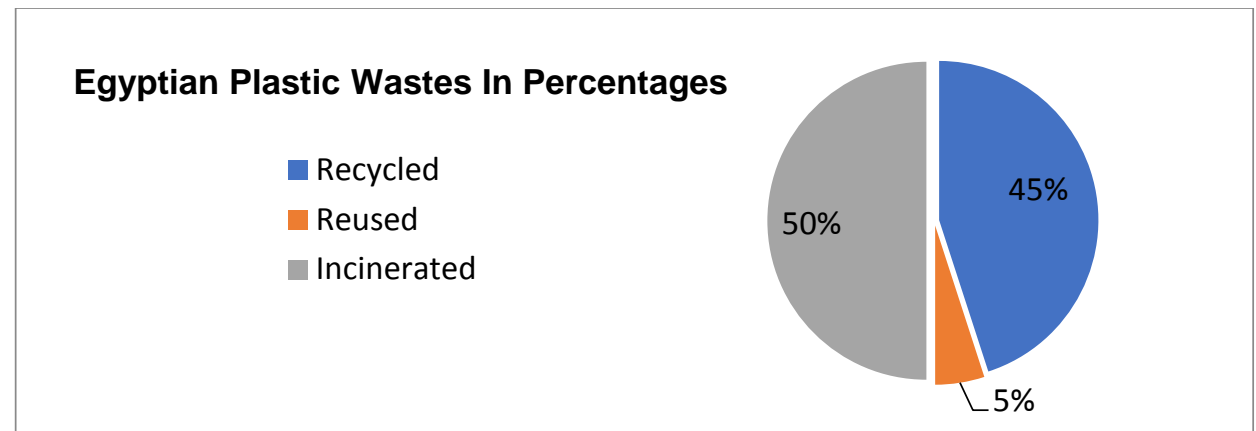

Fig.6. Egyptian plastic wastes in percentages (EgyptToday, 2018)

As stated by Nagwa El Maanawy, head of the Egyptian Plastic Technology Center, which is affiliated with the Ministry of Trade and Industry, Plastic wastes is generated in huge amounts about 970 thousand tons where forty five percent is recycled, only five percent reused, and fifty percent of plastic wastes is not sorted but instead incinerated, which is very harmful to the environment as shown in Figure 6.

Rink et al., (1999) mentioned that manufacturers should carefully assess the product life cycle before using the Eco design strategies as it is an important concept in Marketing field showing the peaks and falls of the product. Although, some products grow and fall, others never reach to the final stage. Product life cycle has four phases that begins with Launching the product, Growth phase when sales are increasing by a very high rate, then Maturity phase if sales near the climax but increasing on a slow rate. Lastly, Decline phase when the product falls.

\section{SUMMARY AND CONCLUSION}

This research examines the selection of low impact raw materials as one of the Eco Design strategies while using the Life cycle thinking to assess and reduce the environmental impacts related with plastics use to reach sustainability of needed resources to form a closed loop cycle and consequently circular economy. Further examination as well as ecodesign tools will be used to study the situation in the Egyptian market in details and provide realistic solutions with smart, achievable objectives, and to set time-framed schedule.

The EU strategies to reduce plastic wastes percentage are identified to be used as a benchmark to achieve the circular economy system in the Egyptian plastic industry. One of those strategies is the Green-dot system that was adopted by many European countries along with Turkey, where companies pay a fee to finance the collection, sorting and recovery of packaging waste as reducing the usage of plastics will obviously cut costs and resources invested in plastics production (Wecker, 2018). With integration and promotion of eco-design principles Egyptian society and economy could benefit in reduced use of plastic, use of environmentally friendlier materials as well as reduced amount of plastic waste as well as energy needed for its processing.

\section{REFERENCES}

Association of Plastics Manufacturers. 2018. PlasticsEurope - How plastics are made. [Online] Available at: https://www.plasticseurope.org/en/about-plastics/whatare-plastics/how-plastics-are-made [Accessed 2511 2018].

Earth Day Network. (2018). Top 20 Countries Ranked by Mass of Mismanaged Plastic Waste / Earth Day Network. [online] Available at: https://www.earthday.org/ 
2018/04/06/top-20-countries-ranked-by-mass-of-mismanaged-plastic-waste/

[Accessed 5 Dec. 2018].

Ec.europa.eu. (2018). Packaging waste statistics - Statistics Explained. [online] Available at: https://ec.europa.eu/eurostat/statistics-explained/index.php/ Packaging_waste_statistics [Accessed 5 Dec. 2018].

Egyptian Plastic exporters and Manufacturers Association. 2009. Egyptian Plastic exporters and Manufacturers Association. [online] Available at: http://www.epema.org/who_we_are.aspx [25.11.2018].

EgyptToday. (2018). Egypt's initiative to eliminate plastic bags. [online] Available at: http://www.egypttoday.com/Article/2/49385/Egypt\%E2\%80\%99s-initiative-toeliminate-plastic-bags [Accessed 4 Dec. 2018].

Hopewell, J., Dvorak, R. and Kosior, E. (2009). Plastics recycling: challenges and opportunities. Philos Trans R Soc Lond B Biol Sci., 364(1526), 2115-2126.

Matsuno, Y., and Kondo, Y, 2008. Corner: J LCA Jpn The Journal of Life Cycle Assessment. Japan. The International Journal of Life Cycle Assessment, 13(1), 1011, DOI: 10.1007/s11367-007-0368-7

B-Corporation. 2018. Resource Guide: Conducting a Life Cycle Assessment (LCA). [online] Available at: http://nbis.org/nbisresources/life_cycle_assessment_thinking/ guide_life_cycle_assessment_bcorp.pdf [Accessed 2 Dec. 2018].

NRDC. (2018). 10 Ways to Reduce Plastic Pollution. [online] Available at: https://www.nrdc.org/stories/10-ways-reduce-plastic-pollution [Accessed 2 Dec. 2018].

Okala.net. (2018). The Ecodesign strategy wheel. [online] Available at: http://www.okala.net/Okala\%20Ecodesign\%20Strategy\%20Guide\%202012.pdf [Accessed 2 Dec. 2018].

Our World in Data. (2018). Plastic Pollution. [online] Available at: https://ourworldindata.org/plastic-pollution\#global-plastic-production [Accessed 2 Dec. 2018].

Oxford Business Group, 2011. Oxford Business Group. [Online] Available at: https://oxfordbusinessgroup.com/overview/manufacturing-might-growing-exportactivity-and-emphasis-local-production-support-transition [Accessed 29.11.2018].

Plastex, 2018. Plastex. [Online]. Available at: http://www.plastex-online.com/overview/ market-background/ [Accessed 2 Dec. 2018].

Rink, D., Roden, D., and Fox, H, 1999. Financial management and planning with the product life cycle concept. Business Horizons, 42(5), 65-72, DOI: 10.1016/s00076813(99)80077-9

Statista. (2018). Global plastic production / Statista. [online] Available at: https://www.statista.com/statistics/282732/global-production-of-plastics-since-1950/ [Accessed 2 Dec. 2018].

Sustainable minds. (2018). [online] Available at: https://app.sustainableminds.com/ learning-center/conducting-sm-lca/stage3-comparing-interpreting-results [Accessed 5 Dec. 2018].

The Conversation. (2018). The world of plastics, in numbers. [online] Available at: https://theconversation.com/the-world-of-plastics-in-numbers-100291 [Accessed 2 Dec. 2018].

Wecker, K. (2018). Plastic waste and the recycling myth. DW Environment, 12.10.2018. 
World Economic Forum (WEF). (2018). The world's plastic problem in numbers. [online] Available at: https://www.weforum.org/agenda/2018/08/the-world-ofplastics-in-numbers [Accessed 2 Dec. 2018].

World Energy Council (WEC). 2016. World Energy Resources - About the Resources Work Programme. WEC work programme. [online]. Available on: https://www.worldenergy.org/work-programme/strategic-insight/survey-of-energyresources-and-technologies/ [Accessed 5.12.2018]. 